\title{
Redox and productivity controls on the cadmium isotope composition of organic-rich sediments
}

\author{
LOGAN A TEGLER ${ }^{1}$, SUNE GRØNLUND NIELSEN ${ }^{1}$,
} CHADLIN M OSTRANDER ${ }^{1}$, ARIEL ANBAR ${ }^{2}$, BRIAN KENDALL $^{3}$, JEREMY OWENS ${ }^{4}$, LARRY PETERSON ${ }^{5}$, FLORIAN SCHOLZ ${ }^{6}$ AND TRISTAN J HORNER ${ }^{1}$

${ }^{1}$ Woods Hole Oceanographic Institution

${ }^{2}$ Arizona State University

${ }^{3}$ University of Waterloo

${ }^{4}$ Florida State University

${ }^{5}$ University of Miami

${ }^{6}$ GEOMAR Helmholtz Centre for Ocean Research Kiel

Presenting Author: ltegler@mit.edu

Cadmium (Cd) isotopes are a novel proxy for productivity in the geological past, but the extent to which local redox conditions affect sedimentary $\mathrm{Cd}$ isotope compositions is uncertain. We analyzed the $\mathrm{Cd}$ isotope composition of modern sediments to provide a framework with which to interpret ancient environments. In the modern oceans, dissolved $\mathrm{Cd}$ concentrations and isotope compositions show nutrient-like distributions; phytoplankton assimilate lighter-mass $\mathrm{Cd}$ isotopes in surface waters, leaving the residual seawater enriched in heavier-mass isotopes. Therefore, if exported and preserved in underlying sediments, $\mathrm{Cd}$ isotopes associated with organic matter derived from surface waters could record changes in nutrient utilization and productivity. However, $\mathrm{Cd}$ burial and isotopic values in sediments are also influenced by local redox conditions because $\mathrm{Cd}$ can precipitate directly from seawater in association with sulfide minerals, which may also impart an isotope fractionation. The relative contribution of each process to sedimentary $\mathrm{Cd}$ isotope budgets is underconstrained. Here, we present a survey of $\mathrm{Cd}$ isotope compositions in recent organicrich sediments deposited under a range of redox conditions, spanning oxygenated, anoxic (Cariaco Basin, Peru Margin), and euxinic (anoxic and sulfidic; Cariaco, Black Sea) settings. Sedimentary $\delta^{114} \mathrm{Cd}$ exhibits a range from crust-like values $(\approx 0.0$ $\%$ ) to those of deep seawater ( $\approx+0.3 \%$, rel. NIST SRM 3108$)$. This range is interpreted as reflecting a combination of authigenic $\mathrm{Cd}$ associated with sulfides and $\mathrm{Cd}$ associated with sinking organic matter. Both of these sinks of Cd impart small negative isotope fractionations relative to their sources, though their expression is dependent on reservoir size. Euxinic settings are characterized by quantitative drawdown of $\mathrm{Cd}$ from local deep waters, which is attributed to a higher proportion of sedimentary $\mathrm{Cd}$ associated with sulfides. Cadmium buried in non-euxinic environments reflects variable mixtures of $\mathrm{Cd}$ associated with organic matter and authigenic phases (without quantitative removal of $\mathrm{Cd}$ from deep waters). We discuss prospects for unmixing these sources using other geochemical properties of the sediments (e.g., TOC, TOS, ambient $\left[\mathrm{O}_{2}\right]$ ), and draw on a case study examining organic-rich shales deposited during an ocean oxygenation event in the late Archean. 